\title{
Cross-correlation frequency-resolved optical gating by molecular vibration for ultrashort pulse
}

\author{
Liu, Xing; Niu, Hanben; Liu, Wei; Chen, Danni; Zhou, Binbin; Bache, Morten
}

Published in:

2013 Conference on Lasers \& Electro-Optics Europe \& the International Quantum Electronics Conference (CLEO/Europe-IQEC)

Link to article, DOI:

10.1109/CLEOE-IQEC.2013.6801114

Publication date:

2013

Link back to DTU Orbit

Citation (APA):

Liu, X., Niu, H., Liu, W., Chen, D., Zhou, B., \& Bache, M. (2013). Cross-correlation frequency-resolved optical gating by molecular vibration for ultrashort pulse. In 2013 Conference on Lasers \& Electro-Optics Europe \& the International Quantum Electronics Conference (CLEO/Europe-IQEC) IEEE. https://doi.org/10.1109/CLEOEIQEC.2013.6801114

\section{General rights}

Copyright and moral rights for the publications made accessible in the public portal are retained by the authors and/or other copyright owners and it is a condition of accessing publications that users recognise and abide by the legal requirements associated with these rights.

- Users may download and print one copy of any publication from the public portal for the purpose of private study or research.

- You may not further distribute the material or use it for any profit-making activity or commercial gain

- You may freely distribute the URL identifying the publication in the public portal 


\title{
Cross-correlation frequency-resolved optical gating by molecular vibration for ultrashort pulse
}

\author{
Xing Liu, ${ }^{1,2}$, Hanben $\mathrm{Niu}^{2}$,Wei Liu ${ }^{2}$,Danni Chen ${ }^{2}$,Binbin Zhou ${ }^{1}$, Morten Bache ${ }^{1}$ \\ ${ }^{1}$ Technical University of Denmark, DTU Fotonik, Dept. of Photonics Engineering, DK-2800 Kgs. Lyngby, Denmark \\ ${ }^{2}$ Key Laboratory of Optoelectronic Devices and Systems of Ministry of Education and Guangdong Province, Institute of \\ Optoelectronics, Shenzhen University, Shenzhen, Guangdong 518060, China
}

The frequency-resolved optical gating (FROG) technique is one of the most popular and robust methods for ultrashort laser pulse characterization [1], which involves an experimental apparatus to create a spectrogram of a target pulse resulting from its convolution with a gate function and a retrieval algorithm.

Since a nonlinear frequency mixing crystal is required, the ultrashort pulse measurement is restricted by the achievable phase-matched spectral bandwidth, group velocity mismatch, frequency conversion efficiency, transparent spectral range of the crystal, and material dispersion induced broadening of the pulses. We propose cross-correlation frequency-resolved optical gating (XFROG) technology based on molecular vibration, which is not limited by the wavelengths, and also has high sensitivity for the measurement of the weak pulse.
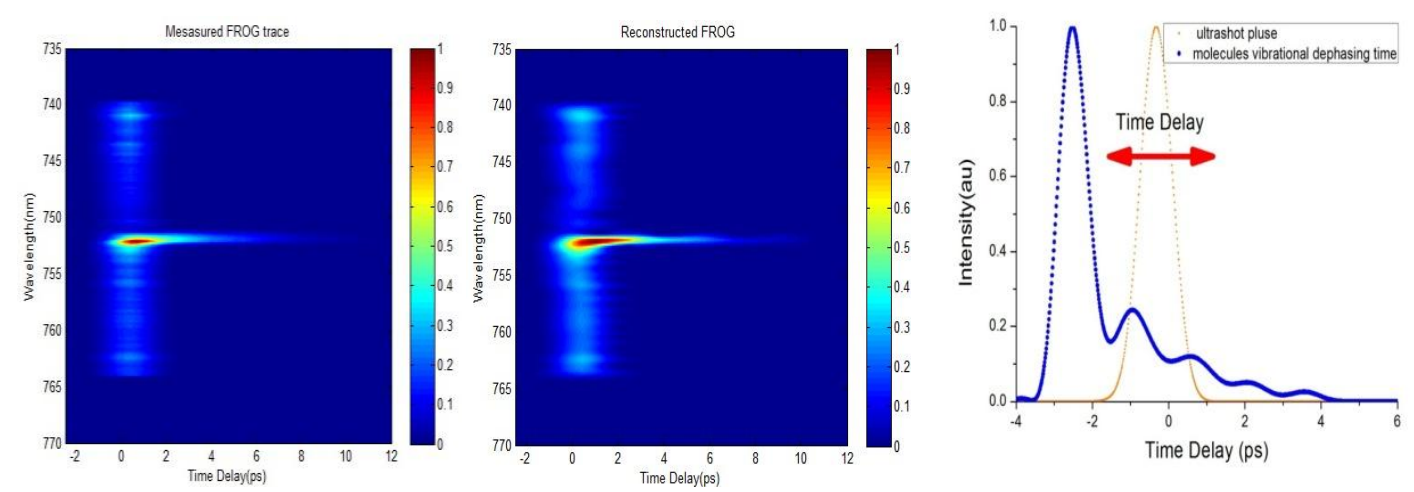

Fig. 1 (a) Measured XFROG trace and (b) reconstructed XFROG trace (c) ultrashort probe pulse and molecules vibrational dephasing time (blue line)

Coherent anti-Stokes Raman scattering (CARS) is a nonlinear four-wave mixing process, vibrational coherence is prepared when the pump and Stokes excitation fields overlap temporally and spatially on a Raman-active sample. The molecules vibration were impulsively stimulated by the laser pulses, which is then field-free revived with dephasing time determined by the molecular constants due to the quantum beatings of the molecular vibrations. The CARS signal results from the scattering of the probe pulse off the excited vibration coherence. We measured the intensity changes of CARS spectral signals for dimethyl sulfoxide versus delay time detected by our broadband time-resolved CARS with a $18 \mathrm{~cm}$ PCF pumped by $783 \mathrm{~nm}$ of wavelength, $150 \mathrm{fs}, 20 \mathrm{~kW}$ laser pulse[2]. Fig. 1 (a) shows one of the T-CARS signals: the vertical axis corresponds to the CARS wavelength, which correlates to the wavenumber. The horizontal axis corresponds to the delay time between the probe and supercontinuum pulses. The process of vibrational coherence is mostly on ps or fs scale $(0.5 \mathrm{ps} \sim 10 \mathrm{ps})$ [3]. We used the molecular dephasing time as the transient gate function, which exhibited a process of exponential decay, and consequently led to a clear XFROG spectrogram. To retrieve the probe pulse from the measured XFROG trace, we implemented an iterative Fourier-transform algorithm with a generalized projection method. As we can see, the retrieved XFROG trace in the time domain, Fig. 1(c), shows the molecular vibrational dephasing time (blue curve) and the ultrashort pulse (yellow curve).

In summary, we have demonstrated that molecular-vibration-gated XFROG is a powerful technique for the measurement of ultrashort pulses and ultrafast molecular vibration. Since the molecular vibrational coherence time is from fs to ps, we can expect to measure different ultrashort pulse durations by choosing different Raman modes.

\section{References}

[1] R. Trebino, K. W. DeLong, D. N. Fittinghoff, J. N. Sweetser, M. A. Krumbügel, and D. J. Kane, "Measuring Ultrashort Laser Pulses in the TimeFrequency Domain Using Frequency-Resolved Optical Gating," Review of Scientific Instruments 68, 3277-3295 (1997).

[2] Jun Yin, Ling-Yao Yu, Xing Liu,Wan Hui, Lin Zi-Yang, and Han-Ben Niu, "Simultaneous measurements of global vibrational spectra and dephasing times of molecular vibrational modes by broadband time-resolved coherent anti-Stokes Raman scattering spectrography

," Chin. Phys. 20(1), 014206 (2011) ; Xing Liu, Wei Liu, Jun Yin, Hanben Niu , "Optimization of Supercontinuum Sources for Ultra-Broadband TCARS Spectroscopy," Chin. Phys. Lett., 28(3), 034202 (2011).

[3] A. Laubereau and W. Kaiser, "Vibrational Dynamics of Liquids and Solids Investigated by Picosecond Light-Pulses," Rev. Mod. Phys. 50(3), 607-665 (1978). 